\title{
Intramuscular Fiber Conduction Velocity, Isometric Force and Explosive Performance
}

\author{
by \\ Spyridon Methenitis ${ }^{1}$, Gerasimos Terzis ${ }^{1}$, Nikolaos Zaras ${ }^{1}$, \\ Angeliki-Nikoletta Stasinaki ${ }^{1}$, Nikolaos Karandreas ${ }^{2}$
}

\begin{abstract}
Conduction of electrical signals along the surface of muscle fibers is acknowledged as an essential neuromuscular component which is linked with muscle force production. However, it remains unclear whether muscle fiber conduction velocity (MFCV) is also linked with explosive performance. The aim of the present study was to investigate the relationship between vastus lateralis MFCV and countermovement jumping performance, the rate of force development and maximum isometric force. Fifteen moderately-trained young females performed countermovement jumps as well as an isometric leg press test in order to determine the rate of force development and maximum isometric force. Vastus lateralis MFCV was measured with intramuscular microelectrodes at rest on a different occasion. Maximum MFCV was significantly correlated with maximum isometric force $(r=0.66, p<0.01)$, nevertheless even closer with the leg press rate of force development at $100 \mathrm{~ms}, 150 \mathrm{~ms}, 200 \mathrm{~ms}$, and $250 \mathrm{~ms}$ ( $r=0.85, r$ $=0.89, r=0.91, r=0.92$, respectively, $p<0.01$ ). Similarly, mean MFCV and type II MFCV were better correlated with the rate of force development than with maximum isometric leg press force. Lower, but significant correlations were found between mean MFCV and countermovement jump power $(r=0.65, p<0.01)$. These data suggest that muscle fiber conduction velocity is better linked with the rate of force development than with isometric force, perhaps because conduction velocity is higher in the larger and fastest muscle fibers which are recognized to contribute to explosive actions.
\end{abstract}

Key words: human muscle power, electromyography, electrical propagation velocity, muscle strength.

\section{Introduction}

Human muscle explosive performance is determined by a number of muscular factors such as muscular size and morphology, as well as several neural factors such as the motor unit recruitment and firing frequency (Cormie et al., 2011). An essential part of the neuromuscular structure is the system which propagates the action potential along the muscle fibers i.e. the muscle fiber conduction velocity which has been related with maximum isometric strength, however, little is known about its relation with explosive performance. Indeed, muscle fiber conduction velocity detected with surface electromyography is related with maximum isotonic and isometric strength, and time to achieve maximum strength in sedentary healthy individuals or patients (Arendt-Nielsen et al., 1989; Sadoyama and Masuda, 1987; Van der Hoeven and Lange, 1994). The majority of the studies have focused on the function of biceps brachii muscle, while little is known about the possible correlation between muscle fiber conduction velocity and explosive performance in multi-joint actions. For instance, Pozzo et al.

1 - Athletics Laboratory, School of Physical Education \& Sports Science, National and Kapodistrian University of Athens, Greece.

2 - A' Neurology Clinic, Aiginition Hospital, Medical School, of the National and Kapodistrian University of Athens, Greece. 
(2004) reported close correlations between the rate of increase of muscle fiber conduction velocity as detected with surface electromyography and the force production during explosive actions.

In patients with neuromuscular diseases muscle fiber conduction velocity is thought to be determined by the muscle fiber size and type, with larger and type II muscle fibers having higher muscle fiber conduction velocities (Blijham et al., 2006; Farina et al., 2007; Troni et al., 1983). In healthy individuals, type II muscle fibers have greater cross sectional areas and are able to produce higher power output (Aagaard and Andersen, 1998) compared with type I fibers, while during isometric force application muscle size is the major determinant of performance. Hence, muscle fiber conduction velocity should be better correlated with explosive performance than with isometric force.

The rate of force development, especially during the first $0-250 \mathrm{~ms}$ is strongly correlated with explosive performance and is considered as a significant factor of success in many sports (Cormie et al., 2011). Although some evidence links neural function with the rate of force development (Aagaard et al., 2002; Cormie et al., 2011), the relationship between muscle fiber conduction velocity and the rate of force development has received little attention up to now. The purpose of the present study was to investigate the relationship between vastus lateralis muscle fiber conduction velocity measured with intramuscular electromyography at rest and performance in explosive actions, such as the countermovement jump and the leg press maximum isometric rate of force development. It was hypothesized that those individuals with higher muscle fiber conduction velocity would perform better in the explosive tests and that muscle fiber conduction velocity would be better related with explosive performance than with isometric force.

\section{Material and Methods}

\section{Experimental Approach}

Based upon pilot measurements as well as the published data (e.g. correlation coefficients ranging between $r=0.650-0.890$ ), and according to the design of the present study, an a-priori power analysis (G*Power ver. 3.1; Frank Faul, Universitat Kiel, Germany) revealed that at least
15 participants (Cohen, 1988) should be recruited (actual power: 0.958). Participants visited the laboratory five times with three days between each visit. During their first visit, they were examined by a trained physician for limiting health issues, had their body height/mass measured and signed a consent form. They also performed a familiarization session of countermovement jumping (CMJ) and isometric leg press tests. Two more familiarization sessions were completed during the following week. This was followed by the testing session three days later. During their last visit to the laboratory, muscle fiber conduction velocity was examined at rest. All experimental procedures were in accordance with the Declaration of Helsinki and complied with Greek governmental laws for human subjects. The study design was approved by the ethics committee of the SPESP of the University of Athens (n. 98/14).

\section{Participants}

According to the power analysis mentioned above, fifteen healthy female physical education students with no previous experience in strength/power training participated in the study (age $21.1 \pm 0.4$ yrs, body height $165 \pm 4.5 \mathrm{~cm}$, body mass $56.7 \pm 6 \mathrm{~kg}$, BMI $\left.20.8 \pm 1.7 \mathrm{~kg} \cdot \mathrm{m}^{-2}\right)$. After oral and written detailed description of the experimental procedures, the possible discomforts and benefits, they signed an informed consent form to participate in the study.

\section{Procedures \\ Countermovement jumping}

All participants started with a 10 min warm up on a stationary bicycle with moderate intensity and then performed $3 \mathrm{CMJs}$ with submaximal intensity. Subsequently, subjects performed 3 maximal CMJs with 2 min rest between jumps, on a force platform (Applied Measurements Ltd Co. UK, WP800- $1000 \mathrm{~kg}$ weighting platform, $\mathrm{s} / \mathrm{n}: 40245,80 \times 80 \mathrm{~cm}$, sampling frequency $1 \mathrm{kHz}$ ) with free bending of the knees during the downward movement and with arms akimbo, as previously described (Bosco et al., 1983; Zaras et al., 2014). Data from the force platform were recorded and analyzed (Kyowa sensor interface PCD- 320A, Kyowa Electronic Instruments CO., LTD, Japan) in order to calculate jump height and power according to the following equations: Jump height $(\mathrm{cm})=\left((0.5 \cdot \text { flight time })^{2} \cdot 2^{-1}\right) \cdot 9.81$ and Power $(\mathrm{W})=($ body weight + Fmax $) \cdot 9.81 \cdot$ flight 
time (Bosco et al., 1983; Linthorne 2001; Zaras et al., 2014). Signals were filtered using a secondary low pass Butterworth filter with a cutoff frequency of $20 \mathrm{~Hz}$. The best performance in jump height was used for further analysis. The ICCs for jump height and power were 0.87 (95\% CI: Lower $=0.83$, Upper $=0.95)$ and $0.91(95 \%$ CI: Lower $=$ 0.90 , Upper $=0.99$ ), respectively, $\mathrm{n}=13$ (Zaras et al., 2014).

Evaluation of maximum isometric force and rate of force development

Twenty min after the CMJs, maximum leg press isometric force and the rate of force development were evaluated. Participants wearing Olympic weight lifting shoes were seated on a custom made steel leg press chair and placed both their feet on the force platform (Applied Measurements Ltd Co. UK, WP800, 1000 kg weighting platform, $80 \times 80 \mathrm{~cm}$, sampling frequency $1000 \mathrm{~Hz}$ ) which was positioned perpendicularly on a concrete laboratory wall. The knee angle was set at $120^{\circ}\left(180^{\circ}=\right.$ knee full extension) and the hip angle was set at $100^{\circ}$ (Marcora and Miller, 2000; Zaras et al., 2014; 2016). In order to achieve these angles during testing, the distance between the back of the chair and the force platform was adjusted and then recorded during the first familiarization session for each participant according to her leg length. These adjustments were used in the testing session. All participants were instructed to apply their maximum force as fast as possible for $4 \mathrm{~s}$. Three maximum trials were performed with $3 \mathrm{~min}$ intervals. During each attempt they were vocally encouraged to perform their best effort. Variables were calculated (Kyowa sensor interface PCD320A, Kyowa Electronic Instruments CO., LTD, Japan) from the force-time curve, including maximum isometric force, the rate of force development and impulse, as previously described (Aagaard et al., 2002; Andersen and Aagaard, 2006; Zaras et al., 2014; 2016). Maximum isometric peak force was calculated as the greater force generated from the force-time curve. RFD was calculated as the mean tangential slope of the force-time curve in specific time windows of $0-50$, $0-100,0-150,0-200$ and $0-250 \mathrm{~ms}$, following the equations: RFD $\left(\mathrm{N} \cdot \mathrm{s}^{-1}\right)=\Delta$ Force $\cdot \Delta$ Time $^{-1}$ [e.g.: (Force at $120 \mathrm{~ms}-$ Force at $0 \mathrm{~ms}) \cdot(120 \mathrm{~ms}-0 \mathrm{~ms})$ $1]$, while impulse $(\mathrm{N} \cdot \mathrm{s})$, representing the total force-time integral in a given time period, was calculated as the area under the force-time curve $\left(\right.$ Impulse 0 -kms $=\Sigma \mathrm{F}_{0-\mathrm{kms}} \cdot \Delta$ Timekms, $(\mathrm{kms}=50,100$, 150, 200, 250; Aagaard et al., 2001; Zaras et al., 2014, 2016). At all times, the onset of contraction was set at $2.5 \%$ of the difference between baseline and maximum force (RFD - DF Aagaard et al., 2002). The best performance according to the RFD at $150 \mathrm{~ms}$ was used for statistical analysis. The ICC for maximum isometric force, the RFD (overall) and impulse were: ICC $=0.90$ (95\% CI: Lower $=0.86$, Upper $=$ $0.96)$, ICC $=0.92$ (95\% CI: Lower $=0.80$, Upper $=$ $0.98)$ and ICC $=0.93$ (95\% CI: Lower $=0.85$, Upper $=0.98)$, respectively, $\mathrm{n}=13$.

Muscle fiber conduction velocity

MFCV was measured in vastus lateralis, which is described as a good surrogate for the whole quadriceps muscle (Place et al., 2010), one week after the evaluation of power performance. This muscle is involved in many every day and sports activities. Subjects rested at a supine position with both knees slightly $\left(5^{\circ}\right)$ flexed. MFCV was measured at the middle portion of vastus lateralis of the dominant lower extremity, approximately $20 \mathrm{~cm}$ from the mid patella, using an EMG apparatus (Medtronic Functional Diagnostics, Keypoint 31A02, Skovlunde, Denmark) and analysis software (Medtronic Keypoint ${ }^{\circledR}$, NET, version 4.3.505.0). Laboratory room temperature was set at $24^{\circ} \mathrm{C}$ and regularly controlled. This temperature had been proved not to adversely influence MFCV (Van der Hoeven and Lange, 1994). Subjects refrained from physical exercise for 6 hours before the examination and they rested for $30 \mathrm{~min}$ in the same room temperature before initiation of the procedure. A surface stimulation (1-2 mA, $0.2 \mathrm{~ms}$ duration) over the muscle $( \pm 5 \mathrm{~cm}$ in all directions) was performed in order to identify a region of muscle with minimum end-plates, as well as to identify the most likely direction of the muscle fibers. An area of $5 \times 5 \mathrm{~cm}$, without any visible muscle twitch, as well as the direction of muscle fibers were then marked and recorded for the next evaluations (Stålberg, 1979). After skin cleaning with alcohol, a monopolar EMG needle electrode (length 20 $\mathrm{mm}$, diameter $0.45 \mathrm{~mm}$, recording surface 0.30 mm2; Alpine Biomed, Aps, Skovlunde, Denmark, type DCNTM25) was inserted, 5-10 $\mathrm{mm}$ beyond fascia, while a silver surface electrode (as anode) was placed 10-15 mm away (Troni et al., 1983). 
Driven by the direction of the muscle fibers, a concentric needle electrode (length $20 \mathrm{~mm}$, diameter $0.45 \mathrm{~mm}$, recording surface $0.07 \mathrm{~mm} 2$; Alpine Biomed, Aps, Skovlunde, Denmark, type DCNTM25) was placed $4 \mathrm{~cm}$ away from the stimulation needle. The stimulation signal was set at $0.05 \mathrm{~ms}$ duration, $1 \mathrm{~Hz}$ frequency, $2-15 \mathrm{~mA}$ and filtered between $2-20 \mathrm{kHz}$. The concentric electrode was then moved slightly through the muscle at steps of $1 \mathrm{~mm}$, until reproducible spikes greater than $20 \mu \mathrm{V}$ were recorded, which are most likely to be the answer to the muscle stimulation. When these spikes were found, the concentric electrode was stabilized and the stimulation was repeated until at least five identical muscle fiber responses were recorded, in an effort to ensure reproducibility and to avoid any variations caused by voluntary muscle contraction (Blijham et al., 2006). Two to fifteen latencies, which exceeded the criteria of at least $20 \mu \mathrm{V}$ in amplitude, were measured at the positive peaks. Then, the recording needle was intramuscularly moved at steps of $1 \mathrm{~mm}$ in all directions, until a new group of muscle fiber responses was found. MFCV was calculated using the time of the latencies and the distance between the stimulating and recording electrode (Stålberg, 1979).

The row data from each subject were statistically analyzed with descriptive statistics. Recordings identified as outliers or extreme values or theses which were \pm 2 SD below or above the mean values, were excluded from the analysis. An average of $53 \pm 9$ individual muscle fibers from each subject was used in further analysis. Figure 1 shows the frequency distribution of MFCV of the total 798 fibers measured. The bimodal shape reveals the presence of two different MFCV groups. As indicated in previous reports, type II muscle fibers have higher MFCV than type I (Arendt-Nielsen and Zwarts, 1989; Kereshi et al., 1983). Thus, according to this frequency distribution 468 muscle fibers were classified as type I and 330 as type II (cut point set at $5 \mathrm{~m} \cdot \mathrm{s}-1$ ). From each subject, mean (MFCVmean) and maximum MFCV (MFCVmax) of all muscle fibers, as well as mean MFCV of type I (MFCVtype I) and type II (MFCVtype II) muscle fibers separately, were further used in statistics. The ICCs were examined in a subgroup of the participants $(\mathrm{n}=10)$ and ranged between 0.81 $(95 \%$ CI: Lower $=0.87$, Upper $=0.97)$ and 0.98
$(95 \%$ CI: Lower $=0.95$, Upper $=0.99)$.

\section{Statistical Analyses}

Means and standard deviation of the means were used to describe each variable. Descriptive statistics were used for the analysis of the raw data of MFCV from each subject. A Student's ttest for independent samples was used to evaluate differences between mean MFCV of type I and II muscle fibers. A Pearson's product moment correlation coefficient was used to explore the relationships between MFCV and strengthexplosive performance variables (thresholds for significant correlations was $r \geq 0.482$; Müller and Büttner, 1994). The interpretation of the observed correlations was performed according to the Hopkins' ranking: correlations between $0.3-0.5$ were classified as moderate, between $0.51-0.7$ as large, between $0.71-0.9$ as very large and over 0.91 as almost perfect (Hopkins, 2000). Statistical analyses were performed with SPSS Statistics Ver. 20 (IBM Corporation, USA). Two-tails significance was accepted at $\mathrm{p} \leq 0.05$.

\section{Results}

$M F C V$ and performance: Vastus lateralis $\mathrm{MFCV}_{\text {mean }}$ was $4.9 \pm 0.4 \mathrm{~m} \cdot \mathrm{s}^{-1}$. The MFCV $\mathrm{M}_{\text {type I }}$ and $\mathrm{MFCV}_{\text {type II were }} 4.06 \pm 0.2 \mathrm{~m} \cdot \mathrm{s}^{-1}$ and $5.9 \pm 0.3 \mathrm{~m} \cdot \mathrm{s}^{-1}$, respectively $(\mathrm{p}<0.001)$. MFCV $V_{\max }$ was $6.8 \pm 0.7 \mathrm{~m} \cdot \mathrm{s}^{-}$ 1. Countermovement jumping height was $27.4 \pm$ $2.7 \mathrm{~cm}$ and peak power was $2179 \pm 276$ Watt. Maximum leg press isometric force was $1669 \pm 488$ $\mathrm{N}$. The RFD at $50 \mathrm{~ms}, 100 \mathrm{~ms}, 150 \mathrm{~ms}, 200 \mathrm{~ms}$ and $250 \mathrm{~ms}$ was $4867 \pm 2399 \mathrm{~N} \cdot \mathrm{s}^{-1}, 6471 \pm 2279 \mathrm{~N} \cdot \mathrm{s}^{-1}$, $6030 \pm 2116 \mathrm{~N} \cdot \mathrm{s}^{-1}, 5363 \pm 1883 \mathrm{~N} \cdot \mathrm{s}^{-1}$ and $4723 \pm 1658$ $\mathrm{N} \cdot \mathrm{s}^{-1}$, respectively. Impulse for the same time points was $20.4 \pm 9.8 \mathrm{~N} \cdot \mathrm{s}, 265.3 \pm 105.2 \mathrm{~N} \cdot \mathrm{s}, 993 \pm$ $351 \mathrm{~N} \cdot \mathrm{s}, 2235 \pm 801 \mathrm{~N} \cdot \mathrm{s}$ and $4357 \pm 1496 \mathrm{~N} \cdot \mathrm{s}$ respectively.

Correlations between MFCV and explosive performance: Leg press maximum isometric force was significantly correlated with $\mathrm{MFCV}_{\text {mean }}(\mathrm{r}=$ $0.76, \mathrm{p}<0.01), \mathrm{MFCV}_{\text {type II }}(\mathrm{r}=0.59, \mathrm{p}<0.05)$ and $\mathrm{MFCV}_{\max }(\mathrm{r}=0.66, \mathrm{p}<0.01)$. Large correlations were also found between peak power during the $\mathrm{CMJ}$ and MFCVmean $(\mathrm{r}=0.65, \mathrm{p}<0.01)$, MFCVtype II $(r=0.59, \mathrm{p}<0.05)$ and MFCV $\max (\mathrm{r}=0.62, \mathrm{p}<$ $0.01)$. In contrast, the correlation coefficients between all measures of MFCV and the CMJ height were low and non-significant (Table 1). Significant correlations were found between $\mathrm{MFCV}_{\text {mean }}$ and isometric RFD/impulse 
at 50-250 ms, although the correlations were lower at the RFD50 compared to the other time points (Table 1). Likewise, MFCVtype II and MFCVmax were closely related to RFD/impulse at 50-250 ms (classifications: large, very large and almost perfect), but again the correlation was lower at the RFD50 (Figure 2). In contrast, the correlation coefficients between $\mathrm{MFCV}_{\text {type I }}$ and all measures of leg press evaluation were non-significant.

Table 1

Correlation coefficients (Pearson $r$ ) between MFCV, the leg press isometric rate of force development, impulse, max force, countermovement height and peak power

Isometric Leg Press

\begin{tabular}{|c|c|c|c|c|c|c|c|c|c|c|c|c|c|}
\hline & \multirow{3}{*}{$\begin{array}{c}\text { Max } \\
\text { Isometric } \\
\text { Force }\end{array}$} & \multicolumn{9}{|c|}{ Isometric Leg Press } & \multirow{2}{*}{\multicolumn{3}{|c|}{ Countermovemen }} \\
\hline & & \multicolumn{5}{|c|}{ Rate of force development } & \multicolumn{4}{|c|}{ Impulse } & & & \\
\hline & & $50 \mathrm{~ms}$ & $100 \mathrm{~ms}$ & $150 \mathrm{~ms}$ & $200 \mathrm{~ms}$ & $250 \mathrm{~ms}$ & $50 \mathrm{~ms}$ & $100 \mathrm{~ms}$ & $150 \mathrm{~ms}$ & $200 \mathrm{~ms}$ & $250 \mathrm{~ms}$ & Height & $\begin{array}{l}\text { Peak } \\
\text { Power }\end{array}$ \\
\hline$M{ }^{\prime} C V_{\text {mean }}$ & $0.76^{* *}$ & $0.69^{* *}$ & $0.79^{* *}$ & $0.88^{* *}$ & $0.86^{* *}$ & $0.86^{* *}$ & $0.62^{*}$ & $0.77^{* *}$ & $0.84^{* *}$ & $0.87^{* *}$ & $0.88^{* *}$ & 0.10 & $0.65^{* *}$ \\
\hline MFCV $_{\text {type I }}$ & 0.13 & -0.08 & -0.01 & -0.01 & -0.07 & -0.08 & -0.13 & -0.03 & -0.01 & -0.01 & -0.25 & -0.24 & -0.32 \\
\hline MFCV $_{\text {type II }}$ & $0.59^{*}$ & $0.53^{*}$ & $0.76^{* *}$ & $0.84^{* *}$ & $0.85^{* *}$ & $0.85^{* *}$ & 0.34 & $0.68^{* *}$ & $0.79^{* *}$ & $0.83^{* *}$ & $0.85^{* *}$ & 0.09 & $0.59^{*}$ \\
\hline $\mathrm{MFCV}_{\max }$ & $0.66^{* *}$ & $0.64^{*}$ & $0.85^{* *}$ & $0.89^{* *}$ & $0.91^{* *}$ & $0.92^{* *}$ & $0.53^{*}$ & $0.77^{* *}$ & $0.87^{* *}$ & $0.90^{* *}$ & $0.92^{* *}$ & 0.30 & $0.62^{*}$ \\
\hline
\end{tabular}

MFCV: Muscle Fiber Conduction Velocity; Mean: mean MFCV of all muscle fibers;

Type I: mean MFCV of type I fibers; Type II: mean MFCV of type II fibers;

Max: maximum MFCV of all muscle fibers; ${ }^{*} p<0.05,{ }^{* *} p<0.01$.

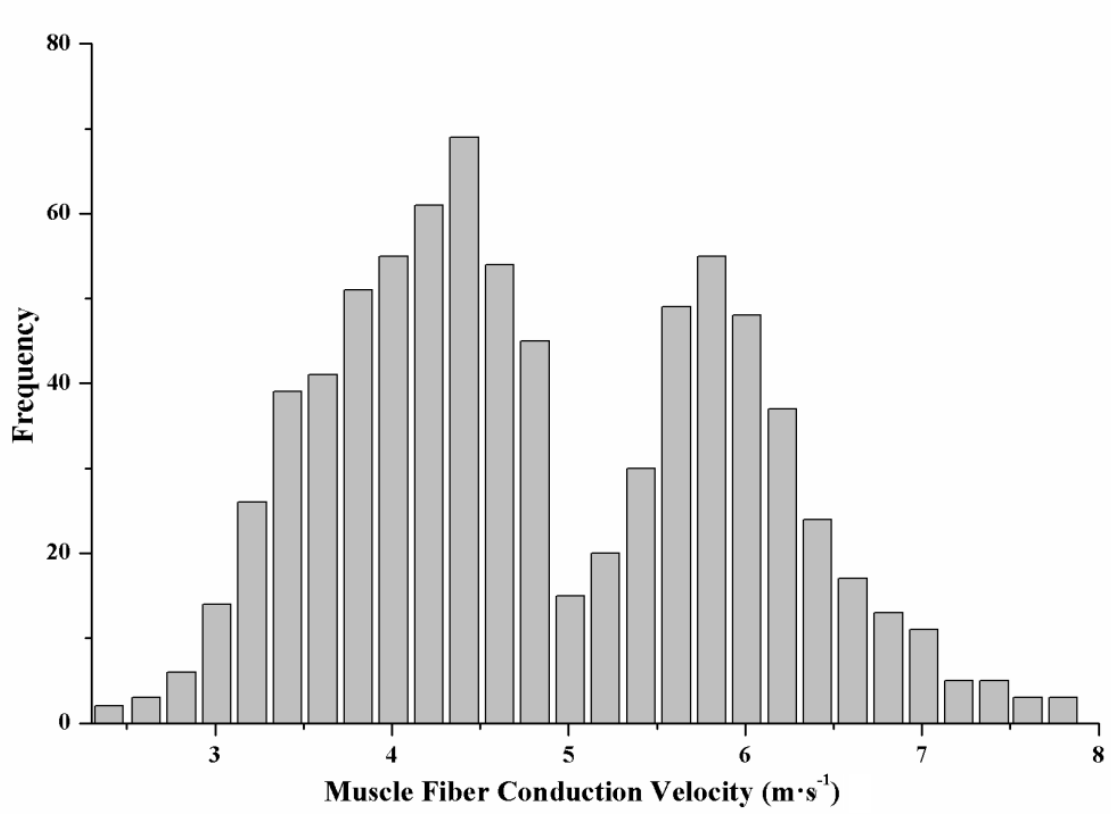

Figure 1

Muscle fiber conduction velocity frequency distribution for the entire 798 fibers measured in the study $(n=15)$. 

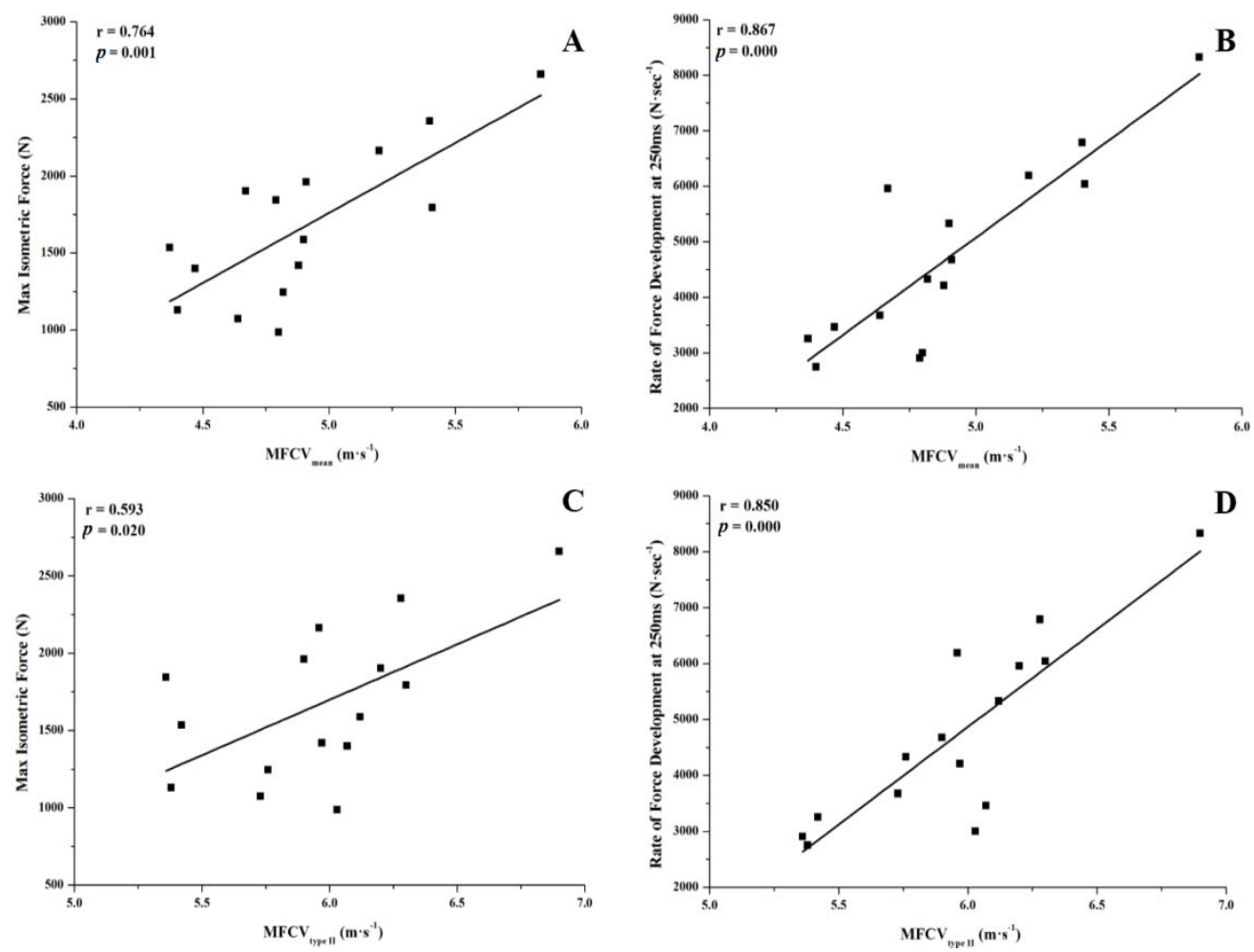

Figure 2

Correlation between average muscle fiber conduction velocity ( $\left.M F C V_{\text {mean }}\right)$

with (A) maximum isometric force, $(B)$ max rate of force development at $250 \mathrm{~ms}$ and between muscle fiber conduction velocity of the fastest subgroup

of fibers (presumably type II; MFC $V_{\text {type II }}$ ), (C) maximum isometric force, and (D) max rate of force development at $250 \mathrm{~ms}$.

\section{Discussion}

The main finding of the present study was a close correlation between resting intramuscular muscle fiber conduction velocity and the leg press rate of force development from $100 \mathrm{~ms}$ to $250 \mathrm{~ms}$. The rate of force development is thought to be determined to a large part by the type and size of muscle fibers, with individuals having a higher percentage and cross sectional area of type II muscle fibers achieving better performance in activities demanding high rates of force development (Aagaard and Andersen, 1998; Andersen et al., 2010). The current results show that explosive performance is strongly correlated with muscle fiber conduction velocity of the fastest, but not with the slowest group of fibers. This is in accordance with the notion that in fast and forceful movements, the fastest fibers contribute to the production of higher muscular power.

In explosive activities, the rate of force development seems to be a key factor as it allows for the implementation of a higher percentage of maximum strength in the early phase $(\mathrm{ms})$ of movement (Aagaard et al., 2001; 2002; Cormie et al., 2011). Previous studies suggested that the neural system is a strong determinant factor of the rate of force development (Aagaard et al., 2001 2002; Cormie et al., 2011). The present study provides evidence of a close relationship between the performance in such fast and forceful 
activities and muscle fiber conduction velocity of the vastus lateralis especially in a multi-joint activity, which better resembles daily activities or sports specific movements compared with singlejoint actions. Also, the current data show that the rate of force development is closely linked with maximum velocity with which the action potential can be propagated along muscle fibers. It seems that individuals with muscle fibers with higher muscle fiber conduction velocities would have a higher rate of force development. Interestingly, the correlation between MFCV and the RFD at $50 \mathrm{~ms}$ was lower than that at later points in the force time curve. This may be due to the participants' non-efficient recruitment of type II muscle fibers during the initial $\mathrm{ms}$ of an explosive contraction since they were not powertrained.

Countermovement jumping height did not correlate with muscle fiber conduction velocity, most likely because jumping height may be affected by non-neuromuscular biological factors such as the mass of the adipose tissue. Instead, jumping power is strongly affected by muscle quality and quantity (Cormie et al., 2011) which, according to the present data, may also include the MFCV. Previous studies reported a close link between jumping power and the proportion (Bosco et al., 1983) and size (Hakkinen et al., 1984) of type II muscle fibers, which are known to have higher velocities of action potential propagation (Arendt-Nielsen and Zwarts, 1989; Clausen, 2003; Kereshi et al., 1983). The present data provide further evidence for the link between muscle fiber conduction velocity especially of the fastest fibers (e.g. MFCVtype II and MFCVmax) and mechanical power during jumping.

Moderate, but significant correlations between muscle fiber conduction velocity and maximal voluntary strength have been reported before (Sadoyama and Masuda, 1987; Van der Hoeven and Lange, 1994). However, these studies reported only on average muscle fiber conduction velocities, in single joint actions and mostly on patients with neuromuscular disorders; moreover, MFCV was evaluated during maximal voluntary contractions, when MFCV is higher compared to resting conditions (Pozzo et al., 2004; Sadoyama and Masuda, 1987; Stålberg, 1966). In addition, muscle fiber conduction velocity in these studies was evaluated by surface electrodes, which could not provide detailed information of MFCV such as the maximum conduction velocities or conduction velocities corresponding to type I or type II muscle fibers (Stålberg, 1979; Troni et al., 1983). Therefore, one of the most interesting findings of the present study was the significant correlation between resting intramuscular conduction velocity of the fastest fibers and maximal isometric strength, indicating that in healthy individuals performing multi-joint efforts, when the fastest fiber population is recruited maximal isometric strength is attained.

Despite large correlations found between MFCV and the rate of force development or CMJ power, it may not escape attention that MFCV was measured in only one of the quadriceps muscles. Although the vastus lateralis is an accessible muscle and is thought to be a good surrogate for the quadriceps musculature (Place et al., 2010), several other muscles are involved both in the leg press as well as in countermovement jumping (Nagano et al., 2005). Electromyographic data from other muscles of the lower extremities would be very valuable, however, this was not possible in the current set-up. Another limitation of this study was the lack of information regarding the vastus lateralis muscle fiber type composition which would have provided a better insight into the physiological basis of the current results.

In conclusion, the results of the present study indicate that the velocity with which the neural signals travel along the surface of the muscle fibers is linked with performance during multi-joint explosive actions. Moreover, muscle fiber conduction velocity is better related to the rate of force development than to maximum isometric force and this may be linked with the recruitment of fast muscle fibers during explosive actions.

\section{Acknowledgements}

The authors express our gratitude to the participants of the study. 


\section{References}

Aagaard P, Andersen JL. Correlation between contractile strength and myosin heavy chain isoform composition in human skeletal muscle. Med Sci Sports Exerc, 1998; 30(8): 1217-1222

Aagaard P, Simonsen EB, Andersen JL, Magnusson P, Dyhre-Poulsen P. Increased rate of force development and neural drive of human skeletal muscle following resistance training. J Appl Physiol, 2002; 93(4): 1318-1326

Aagaard P, Andersen JL, Dyhre-Poulsen P, Leffers AM, Wagner A, Magnusson SP, Halkjær-Kristensen J, Simonsen EB. A mechanism for increased contractile strength of human pennate muscle in response to strength training: changes in muscle architecture. J Physiol, 2001; 534(Pt. 2): 613-623

Andersen LL, Aagaard P. Influence of maximal muscle strength and intrinsic muscle contractile properties on contractile rate of force development. Eur J Appl Physiol, 2006; 96(1): 46-52

Andersen LL, Andersen JL, Zebis MK, Aagaard P. Early and late rate of force development: differential adaptive responses to resistance training? Scand J Med Sci Spor, 2010; 20(1): 162-169

Arendt-Nielsen L, Zwarts M. Measurement of muscle fiber conduction velocity in humans: techniques and applications. J Clin Neurophysiol, 1989; 6(2): 173-190

Arendt-Nielsen L, Mills KR, Forster A. Changes in muscle fiber conduction velocity, mean power frequency, and mean EMG voltage during prolonged submaximal contractions. Muscle Nerve, 1989; 12(6): 493-497

Blijham PJ, Ter Laak HJ, Schelhaas HJ, Van Engelen BG, Stegeman DF, Zwarts MJ. Relation between muscle fiber conduction velocity and fiber size in neuromuscular disorders. J Appl Physiol, 2006; 100(6): 18371841

Bosco C, Luhtanen P, Komi PV. A simple method for measurement of mechanical power in jumping. Eur J Appl Physiol Occup Physiol, 1983; 50(2): 273-282

Bosco C, Komi PV, Tihanyi J, Fekete G, Apor P. Mechanical power test and fiber composition of human leg extensor muscles. Eur J Appl Physiol Occup Physiol, 1983; 51(1): 129-135

Clausen T. $\mathrm{Na}^{+}-\mathrm{K}^{+}$pump regulation and skeletal muscle contractility. Physiol Rev, 2003; 83(4): 1269-1324

Cohen J. Statistical power analysis for the behavioral sciences (2nd ed). Hillsdale, NJ: Erlbaum; 1988

Cormie P, Mc Guigan MR, Newton RU. Developing maximal neuromuscular power: Part 1-biological basis of maximal power production. Sports Med, 2011; 41(1): 17-38

Farina D, Ferguson RA, Macaluso A, De Vito G. Correlation of average muscle fiber conduction velocity measured during cycling exercise with myosin heavy chain composition, lactate threshold, and $\mathrm{VO}_{2 \max }$ J Electromyogr Kines, 2007; 17(4): 393-400

Hakkinen K, Alen M, Komi P. Neuromuscular, anaerobic, and aerobic performance characteristics of elite power athletes. Eur J Appl Physiol Occup Physiol, 1984; 53(2): 97-105

Hopkins WG. Measures of reliability in sports medicine and science. Sports Med, 2000; 30(1): 1-15

Kereshi S, Manzano G, Mc Comas AJ. Impulse conduction velocities in human biceps brachii muscles. Exp Neurol, 1983; 80(3): 652-662

Linthorne NP. Analysis of standing vertical jumps using a force platform. Am J Phys, 2001; 69: 1198-1204

Müller R, Büttner P. A critical discussion of intraclass correlation coefficients. Stat Med, 1994; 13(23-24): 24652476

Marcora S, Miller MK. The effect of knee angle on the external validity of isometric measures of lower body neuromuscular function. J Sport Sci, 2000; 18(5): 313-319

Nagano A, Komura T, Fukashiro S, Himeno R. Force, work and power output of lower limb muscles during human maximal-effort countermovement jumping. J Electromyogr Kines, 2005; 15(4): 367-376

Place N, Casartelli N, Glatthorn JF, Maffiuletti NA. Comparison of quadriceps inactivation between nerve 
and muscle stimulation. Muscle Nerve, 2010; 42(6): 894-900

Pozzo M, Merlo E, Farina D, Antonutto G, Merletti R, Di Prampero PE. Muscle-fiber conduction velocity estimated from surface EMG signals during explosive dynamic contractions. Muscle Nerve, 2004; 29(6): 823-833

Sadoyama T, Masuda T. Changes of the average muscle fiber conduction velocity during a varying force contraction. Electroencephalogr Clin Neurophysiol, 1987; 67(5): 495-497

Stålberg E. Propagation velocity in human muscle fibers in situ. Acta Physiol Scand, 1966; 287: 1-112

Stålberg E. Single fibre electromyography. Trends Neurosci, 1979; 2(0): 185-188

Troni W, Cantello R, Rainero I. Conduction velocity along human muscle fibers in situ. Neurology, 1983; 33(11): 1453-1453

Van der Hoeven JH, Lange F. Supernormal muscle fiber conduction velocity during intermittent isometric exercise in human muscle. J Appl Physiol, 1994; 77(2): 802-806

Zaras ND, Stasinaki AE, Krase AA, Methenitis SK, Karampatsos GP, Georgiadis GV, Spengos KM, Terzis GD. Effects of tapering with light vs. heavy loads on track and field throwing performance. J Strength Cond Res, 2014; 28(12): 3484-3495

Zaras ND, Stasinaki AE, Methenitis SK, Krase AA, Karampatsos GP, Georgiadis GV, Spengos KM, Terzis GD. Rate of force development, muscle architecture, and performance in young competitive track and field throwers. J Strength Cond Res, 2016; 30(1): 81-92

\section{Corresponding author:}

\section{Spyridon Methenitis ( )}

Athletics Laboratory School of Physical Education \& Sport Science,

National and Kapodistrian University of Athens

Ethnikis Antistassis 41, 172 37, Daphne, Athens, Greece

Tel.: +30-210-7276194

Fax: +30-210-7276105

E-mail: smetheni@phed.uoa.gr 